\title{
The 70th anniversary of automated radionuclide imaging
}

\section{Ralph McCready ${ }^{1}$ (D)}

Received: 12 June 2019 / Accepted: 21 June 2019 / Published online: 16 August 2019

(C) Springer-Verlag GmbH Germany, part of Springer Nature 2019

This year Satoshi Minoshima, President of the Society of Nuclear Medicine and Molecular Imaging, wrote that 'Nuclear medicine has been a trailblazer in imaging and sciences for more than a century' [1]. In the 1950s, before the Internet, faxes and texting, trailblazing in nuclear medicine was taking place on both sides of the Atlantic, but without the benefits of instant communication by Internet, fax or text.

Next year, 2020, will mark the 70th anniversary of the start of automatic radionuclide imaging and the beginning of nuclear medicine and molecular imaging as we understand it today.

Until the 1950s, radionuclide studies concentrated on physiological measurements of body function. The first attempts at studying the distribution of radionuclides within organs used hand-held Geiger-counter detectors. The count rates were plotted on graph paper and isocount lines were drawn. Manual linear scanning was reported in the British Journal of Radiology in November 1948. Ansell and Rotblat [2] evaluated a retrosternal mass seen on X-ray with manual linear Geiger-counter scanning and 90 microcuries of ${ }^{131} \mathrm{I}$ in a solution of $2 \mathrm{mg}$ inert iodine.

The first documented automatic scanner radionuclide images of radioiodine in the female human thyroid were presented by Ziedses des Plantes, a Dutch neuroradiologist, at the International Congress of Radiology in London in June 1950. Made in Holland, (Fig. 1) the apparatus for 'indirect autoradiography' used a shielded Geiger-Müller tube of $5 \mathrm{~cm}$ length and a single-hole aperture of $1.5 \mathrm{~cm}$ moving at a constant speed zig-zag relative to the patient's thyroid [3-5]. Ziedses des Plantes used an electrochemical method of recording the activity, with a lead stylus and paper moistened with a solution containing potassium iodine, potassium bromide, and

This article is part of the Topical Collection on Editorial

V. Ralph McCready

ralph@icr.ac.uk

1 Institute of Cancer Research, 123 Old Brompton Road, London SW7 3RP, UK

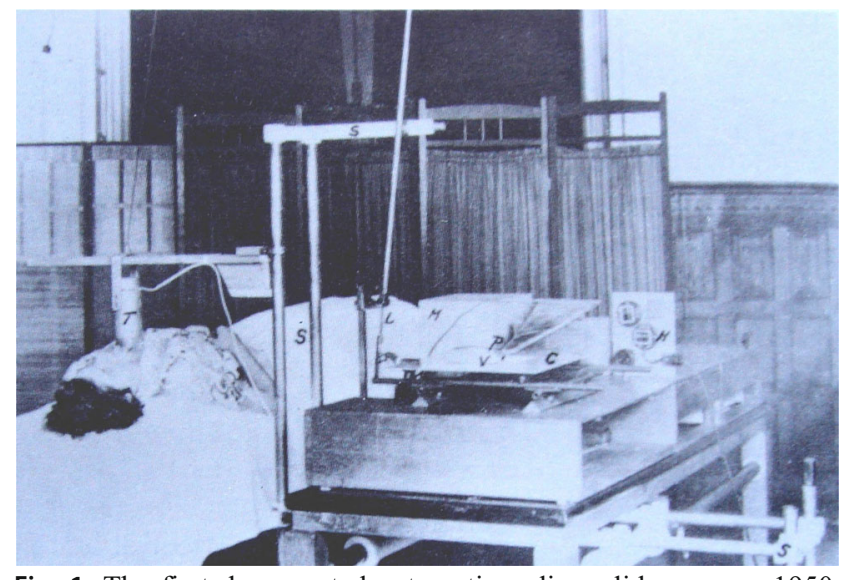

Fig. 1 The first documented automatic radionuclide scanner 1950 . Reprinted from Selected works of B G Ziedes des Plantes Amsterdam: Excerpta Medica, B G Ziedes des Plantes Direct and indirect radiography pp 199-204 1973

dextrene. Unfortunately, the automatic radionuclide scanner received little attention at the time.

In July 1951 at the Oxford Isotope Techniques Conference, Val Mayneord from the Institute of Cancer Research in London demonstrated 'a method of making visible the distribution of radioactivity from a source of ionising radiation'. The proceedings were published in the UK by Her Majesty's Stationery Office for the princely sum of $£ 210$ s $0 \mathrm{~d}$ (or by post $£ 211$ s $0 \mathrm{~d}$ ).

The apparatus, originally designed for imaging brachytherapy sources, was soon used to image radioiodine in the thyroid. Interestingly, it had a novel scanning mechanism where the head with two Geiger counter detectors (one for background radiation subtraction) was mounted on a gimbal. The motion of the head was brought about by two rotating cams being arranged so that one produced a scan along a vertical axis and the other along a horizontal axis. For the raster display, two cathode ray tubes were used; one with long persistence for viewing, and the other with short persistence for photography. This clever but rather complicated device was soon replaced with a rectilinear scanner frame similar to that used by Cassen $[5,6]$ but using a novel continuous detector 
movement with an Archimedean spiral drive. Eventually, the original 1951 scanner was cannibalized, the detector being replaced by an ultrasound probe to develop an automated high-resolution ultrasound tomographic breast scanner. This was presented at the 1973 British Institute of Radiology (BIR) annual meeting [7], in the same session as the first announcement of the CT scanner by J Ambrose and G Hounsfield [8]. It is not hard to guess which innovation had the most attention. Real-time ultrasound soon replaced our attempts at automating ultrasound high-resolution tomographic breast imaging, and the scanner no longer exists. However, the original CT brain scanner shown by Dr. Jamie Ambrose at the 1973 BIR Conference can be seen in the Science Museum in London.

In the early devices, the count rate could be very high, and electronic scalers were used to increase the number of counts per tap of the printer. The original scalers (and Geiger counters) were made by EKCO (E.K. Cole Ltd) based in Southendon-Sea, near Essex in England. Later, this firm made one of the first European Anger-type gamma cameras with a pinhole collimator 5-inch crystal and seven photomultiplier tubes in $1960[9,10]$. Images of the thyroid uptake of 25 microcuries of I-131 were superimposed on the photograph of the patient's neck. The camera was capable of distinguishing point sources $2 \mathrm{~cm}$ apart at $10 \mathrm{~cm}$ from the pinhole!

In America, Benedict Cassen published images of the thyroid using radioiodine and a rectilinear scanner frame with a tapper output on paper mechanism. The article was published in Nucleonics in August 1951 [5]. In Europe, early 'home made' scintigraphic devices were being made. In France Kellersholn et al. used a scanner with an oscilloscope to depict the radionuclide distributions [11]. In Eastern Europe, one of the first home-made scanners was manufactured in the workshop of Palacky University, Olomonc, Czechoslovakia.

Soon, the insensitive Geiger counters in the scanners were replaced by small scintillation crystals, and various manufacturers started to make more sophisticated versions of the original home-built scanners. Siemens in Erlangen produced their Nucleograph in 1958, and later the Scintimat; SELO Mecaserto in Italy produced their DS series, Frieseke and Hopfner (Bonn Germany) made their Universal Scintigraph FH-96 from the prototype developed by Dr. Cuno Winkler (Bonn), and in France Massiot Philips developed their scanner. Philips Medical Systems Eindhoven Netherlands manufactured a wholebody system with 84 detectors in an array $60 \mathrm{~cm}$ wide. In the UK, the first commercial scanner was made by Isotope Developments Ltd., based on the home-made scanner created by Mallard and Peachey $[12,13]$. This scanner used a floating table, a fixed detector, and a colour print-out.

In America, the Picker MagnaScanner was manufactured from 1959. Together with the introduction of Tc $-99 \mathrm{~m}$, it helped to make radioactive imaging a routine procedure throughout the world. The output included a colour-ribbon mechanism which moved over the tapper depending upon the count rate. This enhanced the display of areas with different count rates (Fig. 2).

The Magnascanner also had an output using a light source and a sheet of X-ray film called a Photoscan. A clever count-rate differential device (CRD) which enabled the visualisation on the photographic film of very low lesion uptakes above background radiation (Fig. 3). This was particularly useful in brain scanning with the non-specific radiopharmaceuticals available at that time. Originally the scanner had a 3-inch crystal, but this was upgraded to a much heavier detector with a 5-inch crystal, using the original chassis and height-adjustment mechanism. Apparently the much heavier detector slowly descended towards a surprised but uninjured patient in a London hospital. A rapid modification to the rack and pinion solved the problem.

One of the more interesting organ scans was that of the pancreas (Fig. 4). The only radiopharmaceutical available for pancreas imaging was Se-75 methionine. Unfortunately, the selenomethionine was also taken up by the liver, which often overlapped the pancreas. To get around this problem, a ratio subtract device was made which used the Tc $99 \mathrm{~m}$ colloid in the liver to cancel out the methionine in the liver, leaving only the image of the pancreas. Developed by Kaplan et al. [14] in the USA, it was refined in the Institute of Cancer Research in Sutton UK as a home-made analogue scanner to image brain and pancreatic tumours $[15,16]$. When gamma cameras were introduced, the same principle was used with the help of computers to also image the parathyroids.

Surprisingly, the use of positrons for imaging had already started in the early 1950s [17]. In 1951, Wrenn, Good, and Handler reported the use of two NaI Tl detectors for the localization of ${ }^{64} \mathrm{Cu}$ phthalocyanime in brain tumours [18]. Soon, Brownell and Sweet published their first positron-imaging

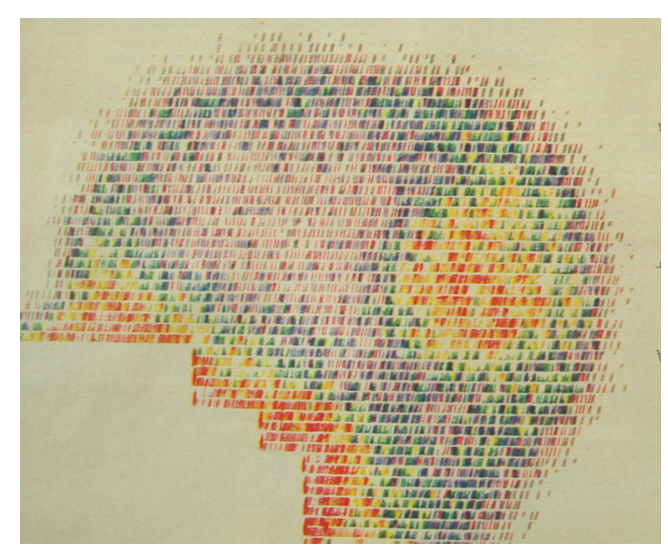

Fig. 2 Colour rectilinear brain scan following $7.7 \mathrm{mCi} \mathrm{Tc} 99 \mathrm{~m} \mathrm{O}_{4}$ 


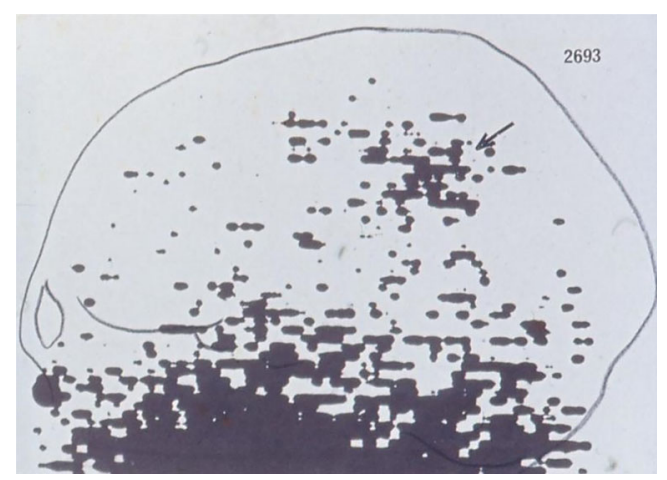

Fig. 3 Hg-197 neohydrin brain photoscan using the CRD to enhance the minimal increase in activity (arrowed) in a brain tumour

device to record three-dimensional data of the brain in their 1953 paper Localization of brain tumours with positron emitters in the no-longer-published magazine Nucleonics. This was the beginning of positron emission tomography [19]. The use of positrons greatly improved the resolution and sensitivity of imaging diagnosis. In 1959, Mallard and Peachey used their automatic scanner with dual positron detection using $1.5^{\prime \prime} \times 1.5^{\prime \prime} \mathrm{NaI}$ crystals to image cerebral tumours with Arsenic 72 and 74 produced by the Medical Research Council Cyclotron at the Hammersmith Hospital in London. It was the first UK successful positron automatic scanner for the diagnosis of cerebral tumours $[12,13]$.

Tomographic imaging improves the contrast ratio between a lesion and the radioactive background. The first tomographic images were produced in 1968 by highly focussed collimators, with scintillators and multiple photomultipliers (Cassen $[4,20]$ ).

Dave Kuhl in the USA built his Mark 2 transverse tomographic isotope scanner in the early 1960s. Two detectors made a line scan in a single plane from multiple angles covering 360 degrees. Computers were yet to be used, and the data were presented by integrating the scan lines on a cathode ray tube display. As the section scanner was upgraded, more detectors were added, increasing the sensitivity. The Mark 3 scanner had four detectors and was

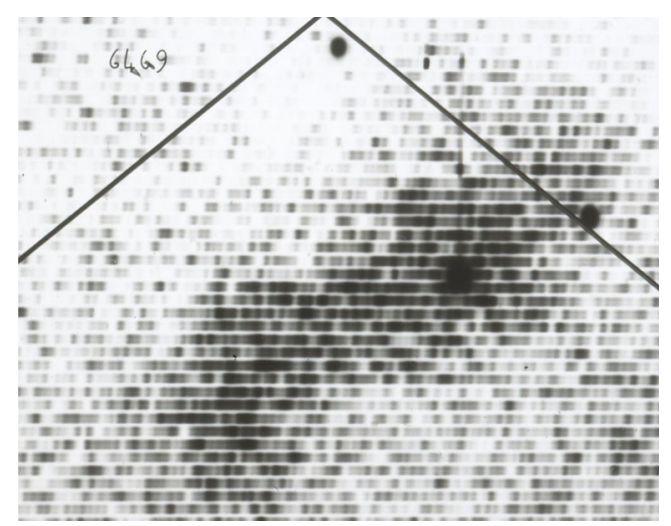

Fig. 4 Se 75 selenomethionine pancreas photoscan using ratio subtraction with Tc $99 \mathrm{~m}$ colloid in the liver completed in August 1968 [21]. In 1969, David Keeling and Andrew Todd-Pokropek from the Nuclear Medicine Department of the Middlesex Hospital London, who had received a grant of $£ 6000$ (English pounds), produced a "section scanner". It was used to perform tomographic examinations, and was thought to be "the first of its kind in all of Europe' [11] (page 80). The scanner was manufactured by J\&P Engineering in Reading UK.

In the UK, John Mallard and his team assembled the Aberdeen Section Scanner (ASS) in 1973 [22, 23]. The scanner was a dual-headed device which could perform conventional rectilinear scans and section or tomographic scans. A punched paper-tape output from both heads was incorporated in the system so that count and position information could be fed into a PDP 8I computer, enabling subsequent image processing and display. A local newspaper reported that 'this device united the ideas of Kuhl and Mallard in an almost inspired way as whole-body scanning and tomography were combined in one unit' [11] (page 128).

Radionuclide scanning completely changed with the invention of the Anger Camera in 1958 [24]. No longer were detectors driven by motors back and forwards over or under a patient. 'Scanning' became 'Imaging'.

The 1950s to 1970s were a golden era for experimenters. An idea could be transformed into a working model for use on patients in a matter of days or weeks. Of course, patient permission was sought and enthusiastically given. With the burden of and risk of litigation from modern health and safety regulations, this can no longer happen [25]. Sadly, for the enthusiastic radionuclide entrepreneurs, the golden era of local/hospital workshop development has gone. Most development now is in the hands of manufacturers.

The good news is that since the first days of automated scanning, images have dramatically improved, especially with PET and novel radiopharmaceuticals, computing and novel imaging devices.

This bodes well for imaging over the next 70 years.

\section{Compliance with ethical standards}

This article does not contain any studies with human participants or animals by the author.

\section{References}

1. Minoshima S. SNMMI leadership update: nuclear medicine: trailblazing imaging practice and sciences for more than a century. $\mathrm{J}$ Nucl Med. 2019;60(5):10N-3N.

2. Ansell G, Rotblat J. Radioactive iodine as a diagnostic aid for intrathoracic goitre. Br J Radiol. 1948;21(251):552-8.

3. Ziedses des Plantes BG. Direct and indirect autoradiography. International Congress of Radiology. London July 1950. In: 
Selected words of BG Ziedses des Plantes. Amsterdam: Excerpta Medica; 1973. p. 199-204.

4. Webb S. From the watching of shadows: the origins of radiological tomography. Bristol and New York: Adam Hilger; 1990.

5. Cassen B, Curtis L, Reed C, Libby R. Instrumentation for I 131 use in medical studies. Nucleonics. 1951;2:46-50.

6. Allen HC Jr, Libby RL, Cassen B. The scintillation counter in clinical studies of human thyroid physiology using I131. J Clin Endocrinol Metab. 1951;11(5):492-511.

7. McCready VR, Hill CR, Milan J. Constant depth ultrasound scanning. Br J Radiol. 1973;46:149-50.

8. Ambrose J, Hounsfield G. Computerized transverse axial tomography. Br J Radiol. 1973;46:148-9.

9. Thomson JA, Boyle JA,Tilston DR, Davis RG. Improved method of thyroid scanning with EKCO gamma camera. Lancet 1964;2:73-4.

10. Murray P, Thomson JA. The use of the gamma camera in the investigation of thyroid disorders. Am J Roentgenol Radium Ther Nucl Med. 1963;90:345-51.

11. Feld M, De Roo M. History of nuclear medicine in Europe. Stuttgart Germany: Schattauer GmbH; 2003.

12. Mallard JR, Peachey CJ. A quantitative automatic body scanner for the localisation of radioisotopes in vivo. Br J Radiol. 1959;32:652-7.

13. Mallard J, Trott NG. Some aspects of the history of nuclear medicine in the United Kingdom. Semin Nucl Med. 1979;9(3):208.

14. Kaplan E, Ben-Porath M, Fink S, Clayton GD, Jacobson B. Evaluation of pancreatic disease by dual channel scanning. J Nucl Med. 1967;8(5):349.

15. Field EO, Cottrall MF, Burn GP, McCready VR. Differential isotope scanning of the brain employing an electronic ratio-subtract technique. Strahlentherapie (Sonderb). 1968;67:62-8.

16. McCready VR, Cottrall MF. Combined pancreas and liver scanning using a double isotope technique. Br J Radiol. 1971;44(527):870-7.
17. Sweet WH. The uses of nuclear disintegration in the diagnosis and treatment of brain tumor. N Engl J Med. 1951;245(23):875-8.

18. Wrenn FR Jr, Good ML, Handler P. The use of positron-emitting radioisotopes for the localization of brain tumors. Science. 1951;113(2940):525-7.

19. Brownell GL, Sweet WH. Localization of brain tumors with positron emitters. Nucleonics. 1953;11:40-5.

20. Eds Gottschalk A, Beck RN. Fundamental problems in scanning. Springfield Illinois: Charles C Thomas; 1968.

21. Kuhl DE, Edwards RQ. Digital processing for modifying and rearranging rectilinear and section scan data under direct observation. In: Medical radioisotope scintigraphy.Vienna:International Atomic Energy Agency;1969.

22. Bowley AR, Taylor CG, Causer DA, Barber DC, Keyes WI, Undrill $\mathrm{PE}$, et al. A radioisotope scanner for rectilinear, arc, transverse section and longitudinal section scanning: (ASS - the Aberdeen Section Scanner). Br J Radiol. 1973;46(544):262-71.

23. Mallard JR. The evolution of medical imaging: from Geiger counters to MRI — a personal saga. Perspect Biol Med. 2003;46(3):354,5.

24. Anger H. Scintillation camera. Rev Sci Instrum. 1958;29:27-33.

25. Ell P, Carrio I, Chiti A. Breaking an unhelpful circle, where innovation and regularia delay clinical practice for patient benefit. Eur J Nucl Med Mol Imaging. 2019;46(7):1397-8.

Publisher's note Springer Nature remains neutral with regard to jurisdictional claims in published maps and institutional affiliations. 